\title{
In Search of Collective Experience and Meaning: A Transcendental Phenomenological Methodology for Organizational Research
}

\author{
Gabriel Henriques
}

Published online: 23 September 2014

(C) The Author(s) 2014. This article is published with open access at Springerlink.com

\begin{abstract}
The Husserlian phenomenological approach to organisational research as a way to understand how collectives experience and mean their work context, is rarely used although, when it is, it often functions as a negative criticism of objectivist methods. The sociological potential of phenomenological concepts to enable understanding of subjective experience of social contexts, and the characterisation of those social contexts through ideal type construction, deserves to be used more extensively in a positive proposal of organisational research methodologies. However, a consistent phenomenological approach-with its inherent qualities that enable the transcendental understanding of subjective phenomena and social objectivity - can be sociologically fruitful only if it benefits from accumulated sociological knowledge, realised by various approaches that discuss macro and micro aspects of organisations. The proposed phenomenological methodology considers both aspects. It takes account of social theories that consider the influences of both the macro environment and institutionalisation on structure and culture through their relationship with collective and individual action. Also, it performs collaboration between two close perspectives which recognise the importance of the subjective meanings of the individuals constituting the collective: Husserl's transcendental phenomenology and Weber's ideal type construction. It also discusses context, participant selection, the concepts of saturation and generalisation, and the applicability of the methodology.
\end{abstract}

Keywords Methodology · Transcendental phenomenological research · Organisational research · Collective experience and meaning · Sociology

G. Henriques ( $\bowtie)$

ISCTE - University Institute of Lisbon (ISCTE-IUL), Edifício ISCTE, Av. das Forças Armadas,

Lisbon, Portugal

e-mail: ghshs@iscte-iul.pt 


\section{Introduction}

The object of study with which I am concerned is sociological; it refers to what the collective experience and meaning of individuals is in a common context, the one in which their agency occurs. In other words, it aims to acknowledge an accurate idea of the cultural and structural environment and implies the acceptance of individual descriptions as being capable of characterising the work context. More than one paradigm accepts it, but with different meanings. On the one hand, from the standpoint of the very influential linguistic perspectives, those descriptions derive from inter-subjective meaning validation that those contextualised individuals perform, and all meaning comes from communicative interaction (Habermas 1984). The broad use of linguistic perspectives in modern social sciences, which are very valuable for the design of communication in organisational structure, gives precedence to social discourse or knowledge; the self is a singular instantiation of social context and the importance of individual specificity and experience is dismissed or devalued. On the other hand, a recent reaction following Weberian perspectives, affirms that along with the social and communicative actor, the acting subject also performs simple behaviour with no meaning as well as solitary meaningful action (Campbell 1996). The self is seen as something constructed through individual interaction and perception in an inter-subjective world. These last perspectives recognise the individual as a communicative actor, but also with his or her own specific biography and way of meaning his or her experiences (Archer 1996).

Contemporary to Max Weber, Edmund Husserl developed his phenomenology as a philosophy during the first third of the 20th century. His influence is recognisable in social theory in almost all approaches, even those of linguistics, which look at individuals for social meaning and thus depart from positivist approaches of classifying and measuring social facts. His phenomenology has been fruitful in successfully illuminating methodological proposals in scientific disciplines, such as psychological research (Giorgi 1985; Hycner 1985; Moustakas 1994). However, it has not yet resulted in a consistent methodology in sociological research.

Pursuing an "active involvement in doing phenomenology" (my emphasis; Steinbock 1997: 131), the aim of this article is to propose a sociological phenomenological methodology from the standpoint of the transcendental phenomenology of Edmund Husserl, based on individuals who have their particular biographies and future perspectives and who share some common context. It pursues, however, the characterisation of a common collective context, being the knowledge of individual idiosyncrasies as just an initial step. The phenomenological concept of the individual, which includes the subjective and inter-subjective aspects of social and non-social experience, as will be shown, allows the construction of a methodology which starts by considering both aspects in individual participants. Then, through the experience and meaning of the individuals, it unveils transcendentally what is typically social. The structure of the methodology contains phases and procedures that are theoretically supported. I also discuss the role of the work context, the role of the researcher, participant selection, interview planning and flow, information saturation, and possibilities of generalisation and applicability. 


\section{Phenomenology and Social Relations}

\section{The Phenomenological Concept of the Individual}

The concept of the individual, which varies according to each specific perspective, determines how each perspective approaches individuals and what it considers in their social lives. The Husserlian ${ }^{1}$ phenomenological perspective provides a specific understanding of the individual in his or her social context that has been influential in social theory and continues to be referential on its own.

A Husserlian phenomenological perspective reflects on conscious phenomena (1970c: 82 ff.) and sees the subject consciousness as just a temporal flux of openness. In each moment, consciousness links the immediate past to the immediate future; or, in the present moment the immediate past locates the context where the immediate future is advanced. Moreover, consciousness has no content in itself and is open to the world outside it (Husserl 1991: $21 \mathrm{ff}$.). This notion of experiencing the external world is very broad (Zahavi 2003: 37; Moran 2001: xivi) and comprises everything in the perceived physical and human world, including the conscious subject body, as well as recalled memories, imaginings, phantasies (Husserl 1970c; 97 ff.), ideal notions, or states of affairs (Husserl 1970b: 18ff.; Husserl 1970c: 263 ff.).

This property of consciousness, this openness, known in philosophy as intentionality, allows the possibility of thought to attend to the stream of consciousness. Intentionality unites the experience of a content of the perceived object or objective situation with subjective ways of perceiving which are learnt by the subject throughout his or her life. This learnt habitus (Husserl 1960: 66f., 127) constitutes itself genetically as a structure with a history of sedimentation which makes possible passive and pre-reflected meaning attribution to present experience (Husserl 2001: 270). In this process, there is the perceived object or objective situation, the subject that is experiencing and the content of the experience. This content-the what of perception-is relative to the object that it is about, but is never exhaustive. It depends on the point of view that draws the attention and the contextual situation, as well as on those learnt ways of perceiving, i.e., on the how of the experience. Thus, the biographical subject, who knows the world and gives attention to its objects, (Husserl 1970c: 81 ff.) produces the objective meaning through perception.

That habitus, as sedimentation of retained meanings, is a structure of perception of the world. It is not a rigid system of determinations, nor a condemnation of thought. It is, instead, open to a horizon of possibilities and choices as well as new experiences and meanings that enhance or alter the sedimented structure throughout life (Husserl 1989: 118 ff.). Therefore, the rigidity or flexibility of the phenomenological habitus is not a theoretical assumption, but an empirical question. Contrarily, the individual's rationality in regard to his or her habitus is a possibility,

\footnotetext{
${ }^{1}$ I will cite or refer to Husserl several times in this paper, always referring to a specific text (when the topic is treated in general) or an exact location in a work, so that the reader may find a context in Husserl's work where he discusses the relevant concepts. However, Husserl revisited the phenomenological concepts several times in his work, producing an increasingly profound analysis.
} 
an empirical question too, but as an infinite task. Thus, the unconscious is not an inscrutable place of hidden meanings, but instead is consciousness not submitted to reflection (Husserl 1970a: 385-387). Hence, rationality is a possibility between reduced or extended reflection.

\section{The Collective and the World of Experience}

Proposing a transcendental sociological project, based on first-person phenomenology, Husserl (1989: 191) argues that communities can be defined in the same way as individuals by way of attributes of consciousness, individual acts, style, memory, will, self. Being subjectivities of a higher level rooted in individuals:

through the interweavings of mutual understanding, social personalities of a higher degree are constituted, related to the common Objective surrounding world as the world to which henceforth all persons find themselves related socially and also as singular individuals. It is the world of their socially significant and perhaps also socially performed labor, and in general it is the world constituted in a manifold of specifically social acts whose sense includes communalities. (Husserl 1989: 336)

Husserl (1989: 281) rejected the idea of the individual as a solipsist monad. He argued that the influence of others, through their thoughts, feelings, and demands, determines the development of a person, independently of the person's ability or inability to discern the degree of that influence. Beside these influences from specific others are influences which present themselves as an indeterminate generality and which belong to the spiritual milieu, as culture, which can be taken passively, or can be positively or negatively favoured. In the same circumstances, this social influence affects different people in different ways. I can see the influence of others' thoughts and feelings in myself, as others' impositions, or, alternatively, as something that I appropriate as mine, which update my habitus.

Therefore the autonomy of reason, the 'freedom' of the personal subject, consists in the fact that I do not yield passively to the influence of others but instead decide for myself. Or again, it consists in this, that I do not let myself be 'drawn' by any other inclinations and drives but instead act freely and do so in the mode of reason. (Husserl 1989: 282)

"To live is always to live-in-certain-of-the-world," which "is always already there, existing in advance for us," as "the 'ground' of all praxis whether theoretical or extra-theoretical" which frame the contexts of experience (Husserl 1970a: 142). The essential structures of this life world as macro structures frame the micro context of experience. Even if the underlying concept of the individual is different, Husserl (1970a: 173f.) affirmed that the validity of different social theories depends on their experiential evidence, i.e., their assertions should correspond to what is lived by individuals and should help to explain social structures. Other theories not complying with this condition do not have the same "dignity" and remain as invalid or mere hypotheses (Husserl 1970a: 41f.). The dialogue between those theories and 
transcendental phenomenological investigation can only improve both. Social theories provide the theoretical understanding of the culture and social structure where human experience develops, but when phenomenological transcendental results are not understandable from the point of view of social theory, either the methodology might be reviewed, or new problems put to social theorists.

This life world, where all experience happens (Husserl 1970a: 121), is a cultural environmental context of experience which is unquestioned and presupposed according to some practical or theoretical interest. The common attitude to this world is one of taking it for granted as the basis for practical living or scientific investigation. From this attitude, common sense and scientific knowledge-when accepted in habitus - are the ways in which we mean our experiences. Communities share similar ways of experiencing the objective world through common meaning as culture. Husserl (1970a: 41-43) asserted that the efficacy of the objective sciences results from the continuous cycle of theories as ideal hypotheses. This is supported by the ideal rigour of mathematical logic and the obtaining of successive confirmations which lead to new hypotheses. These theories, in continuous revision, allow an increasing control of physical reality.

The "dignity" to which Husserl (1970a: 41f.) refers can be achieved through a different attitude where this life world is taken as an object of study (Husserl 1970a: 137-141), and how it is meant is investigated. This presupposes the epoché, i.e., to put in parentheses all mundane knowledge and just describe what is meant and how it is meant, unveiling what is experienced without prejudices. This philosophical approach was the starting point for the definition of a phenomenologicalpsychological method to explore the individual "inner or psychic experience," to study the individual's "pure psychic life as a stratum of intentional experiences belonging to him as an integral part". With this project in mind, the researcher performs an "epoché of validity," i.e., the researcher, as a "disinterested spectator," "abstain[s] from the co-performance of the validity that the perceiving person performs" in order to respect his object of study-the individual's way of experiencing the world, a world where he or she is a "being-in-relation" to others in community (Husserl 1970a: 235-241). "Man, and in communalization mankind, is subjectivity for the world and at the same time is supposed to be in it in an objective and worldly manner," for "the world, is contained as intentional object in exactly the same way that any intention contains its intentional object, [the latter being] strictly inseparable from its relative concreteness" (Husserl 1970a: 262).

\section{Husserl and Weber: Understanding Through Meaning}

The methodology here proposed seeks to use the different ways in which individuals experience the work context to understand the collective context from a sociological perspective. It proposes an ideal concept that may characterise the social collective experience and meaning. As Husserl put it:

The vagueness of such concepts (types), the circumstance that their spheres of application are fluid, does not make them defective; for in the spheres of 
knowledge where they are used they are absolutely indispensable, or in those spheres they are the only legitimate concepts. (1982: 166)

In this case, instead of eidetic imagination,

this ideation is fundamentally different in its essence from the seizing upon an essence by simple 'abstraction' in which a salient 'moment' is raised into the region of essences as something essentially vague, as something typical. (1982: 167)

It is exactly as an abstraction, an ideal construct, that Weber (1949: 81-93) proposes his ideal type in order to conceptually represent the empirical evidence in a consistent and accurate way. Its relation to empirical data lies in the fact that it explains their relations in a clear and understandable way with heuristic and expository purposes, while it might not be possible to find it empirically. It is not an average nor a representation of all characteristics found in the individuals; instead it is formed by the researcher's one-sided accentuation of points of view and by the synthesis of diffuse and discrete phenomena not necessarily present in all the individuals. As an analytical construct made by the researcher through imaginative reflexion, it steps away from the idiosyncratic to the collective producing a useful utopia and approximation. In the methodology proposed here, the researcher will use the individual's eidetic descriptions of social relations, social structures, and cultural aspects to construct a description which represents what is essential and typically collective.

\section{Expression and Meaning}

Each individual finds empathically in his or her subjective experience that the world is also experienced by others, co-experienced in a community of norms, beliefs, and habits, i.e., in common relational structures and shared culture. Those others mean their surrounding world in a similar way even if they have different biographies and participate in other different communities as part of their lives. The experience of the world is collective and normatively structured through common validities, norms, concepts, and practical social relations, but each individual's particular experience maintains its distinctiveness and describes the collective context from his or her own point of view. The researcher gains access to individual descriptions of aspects of that relational context to characterise the collective context.

If, in any social context, individual expression considers that context, then, in an organisational context this is true in the strongest sense. Values and modes of being are prescribed, rules and procedures must be followed, and power is distributed along the hierarchy as well as informally (Meyer and Rowan 1977). In such a context, individuals use descriptions to communicate meaning (Husserl 1969: 22) to a contextual audience, foreseeing social consequences and trying to define or modify the social situation in their favour (Goffman 1959). That is why language should not be taken at face value (Scott 1990). In an interview context, participants hear the researcher's explanations, form an idea of the researcher's objective, recall from their memories similar experiences of their own or referred to by others, define 
the degree of confidence that the interview context deserves and express them in order to define a situation of their own. If they trust in the interview context, they can define a situation in which a freer expression is possible and where the researcher may lead the participants to perform an analysis of their patterns of producing meaning; otherwise, other types of discourse are possible, as we will see later.

\section{Eidetic and Social Typical Conceptualisations}

This analysis of habitus, experience, and meaning is possible in the interview context in a limited, yet adequate way for understanding what is collectively common from what is idiosyncratic.

The proposed methodology aims to investigate a sociological object of studywhat is typical in the variety of each individual's experience and meaning in an organisational collective context. As Giorgi (1985: 11f.) affirms, the everyday world is richer and more complex than a specific perspective (sociological, anthropological, psychological, psychotherapeutic) that is of interest to the researcher and which determines the perspective towards descriptions to be adopted. ${ }^{2}$ With this sociological perspective in mind, in a first step the researcher will help participants to describe their experiences in their own terms. The researcher will ask the participants to detail what was experienced in terms of social relations and contexts, and how it was experienced in terms of valuations and judgements. This helps each participant to acknowledge patterns of meaning in his or her organisational context, in a process that Husserl (1970a: 235-241,385-387) called intentional analysis. Steinbock (1997: 128) explains that the "phenomenological method liberates the acquired meanings of the world (...) by systematically inquiring into how this institution and acquisition come about".

The possibility of a limited, but accurate description of habitus as an intentional sedimentation depends on the researcher's assuming the epoché, performing the suspension of his or her beliefs and validities about what is expressed by a participant who explores his or her habitus. It is expected that the researcher simply assists the participant in performing the intentional analysis while not comparing, interpreting, or executing any validation from the standpoint of the researcher's knowledge. When not understanding what the participant expresses or when looking for confirmation of meanings, the researcher may put open questions to allow the participant to express him or herself better or to go further in expression. Frequently, some beliefs or validities come to the researcher's mind who must suspend them perhaps for further consideration when discussing the research results. The researcher must also have a significant understanding of his or her own habitus so that he or she can acknowledge its influence in the here and now of the interview

\footnotetext{
${ }^{2}$ Weber (1949: 60) had also affirmed that "[a]n attitude of moral indifference has no connection with scientific "objectivity'," so "the problems of social sciences are selected by the value-reference of the phenomena tested" (1949: 21), therefore "without the investigator's evaluative ideas, there would be no principle of election of subject-matter and no meaningful knowledge of the concrete reality" (1949: 82).
} 
and keep it in suspension. Therefore, intentional analysis requires epoché to obtain knowledge about habitus.

Through an eidetic imaginative process, the researcher will then find the invariant structures of those patterns, i.e., the description of what the important social relations, social structures, and cultural aspects are for each individual, as well as the way in which the individual means them. As seen before, Husserl (1982: 167) distinguished between the eidetic process of imaginative variation to determine invariants that characterise each individual's experience and the necessary vagueness, but "absolutely indispensable" social theoretical typifications, expressed as "simple 'abstraction"". Thus, in a second step, the researcher will use the process of construction of the ideal type as described before to characterise the social context. Finally, the researcher will discuss the results in the light of the theories already produced.

\section{Social Environment and Contexts of Experience}

In this section, I briefly discuss some theories which attempt to explain how the social environment influences human experience. According to Husserl (1970a), the experiential evidence should confirm theoretical statements otherwise they are mere hypotheses. Although the focus of this article and space limitations do not permit the discussion of the relation of each of these theories with their experiential evidence, it provides an adequate theoretical framework for the object under study.

\section{Organisations as Open and Institutionalised Systems}

When observing organisations at the highest level of society, modern social theory emphasises the openness of organisations to their environment. This openness, common to different approaches, is the concept that explains how society influences organisational culture and structuration which in turn influence the smaller contexts where human action happens (Scott 2004: 11). These influences arise from rational social myths at global or regional levels that prescribe patterns of values, beliefs, and ways of organising (Meyer and Rowan 1977). When those patterns are not followed it makes organisations look idiosyncratic and unpredictable. Otherwise, when conforming to these "myths," other social agents see organisations as legitimate and their access to resources is easier.

The institutionalisation process powerfully exerts pressure on organisations, prescribing formal culture and structure (Braverman 1974; Gouldner 1971) as ideology. However, individuals still maintain the possibility of opposition in more open or hidden ways, thus redefining power, communication, and behaviour. That is what makes social change possible (DiMaggio 1988) and what the organisation achieves is the result of these diverse influences (Dalton 1959; Merton 1968; Crozier 1967; Silverman 1970). The influence of institutionalisation has been a subject of discussion within various sociological approaches providing a fruitful theoretical context for the discussion of the results of phenomenological transcendental research. In Parsons (1960), culture in organisations is discussed as the 
individuals' integration into that ideology, in Bourdieu (1977) as internalisation of social life into an unconscious habitus, and in Giddens (1984) as learned rules in a dual structure which simultaneously constrains and creates conditions for action. Archer (1996), for her part, asserts that structured social relations determine social rules and proposes a different duality where in a morphogenetic temporal cycle, culture influences structuration and change, and then structure reinforces and limits cultural values, and in each moment both influence agency. Mouzelis (1991) reveals the role of structural level and power and affirms that Giddens' proposal is more suitable for lower structural levels and Archer's for higher structural levels.

In organisations, despite prescribed ideology, values that in fact are shared may be diverse. According to different interactional contexts characterised by specific knowledge, technology, organisational level, function, or geography, specific cultural contexts develop inside the organisation (Sainsaulieu 1977). The influence of organisational ideology on these contextual cultures is a fact, but its degree is an empirical issue. Based on the diversity of contextual cultures that an organisation may include, Sainsalieu (2009: 15) put the question " $[\mathrm{h}]$ ow to create social cohesion in a way that every competitive work situation becomes productive?" This suggests a useful application for the methodology in organisations and which I propose at the end of this paper.

Discourses, Meaning, and Definitions of Situation

Goffman (1959) explained how individuals behave strategically in a social context in order to define a social situation in which they gain the advantages to which they aspire. Scott (1990) refers to highly structured environments and analyses the discourses characteristic of individuals on various levels when in the presence of others of the same or different level. He affirms, unsurprisingly, that those discourses are different and reflect positions of power and strategic definitions of situation. Moreover, individuals who have different discourses in different situations do not see that as contradictory, nor do they experience any cognitive dissonance; instead, they are able to reflect on their behaviour and justify it in strategic terms and in accordance with their idiosyncratic perspectives. Those discourses are then adequate linguistic expressions of the definition of a situation by individuals in the social context. When publicly expressed, those discourses contain strategies to dominate or to resist; when privately expressed in group membership, they contain strategies of resistance to structural power or justifications needed to conform or change (Scott 1990: 183f.).

\section{A Social Phenomenological Methodology}

The Researcher as a Research Tool

The researcher is part of the research. From the initial contact with the organisation to the last interview, the researcher interacts and creates expectations at various levels. Those at the top of the hierarchy will want to know the details of the process 
and what type of outcome to expect. Other levels and collective contexts in the organisation will develop some expectations. The announcement of the research among the potential participants in the organisation and the collective context under investigation, the introduction made by the researcher in the interview, and the way in which the researcher conducts the interview, may affect participants and promote strategic definitions of situations that make the interview relationship more difficult.

Moreover, the researcher has his or her own habitus. If the researcher has difficulty in suspending his or her preconceptions and judgements, or in being compassionate, or in accepting the others' meanings as valid-even if differentways of experiencing the world and the organisation, then the researcher will not engender the necessary trust from the participants. The researcher should have the self-knowledge that allows him or her to be aware of issues of focus and control. Previous experience is important in order to be able to deal with the researcher's own interests, capabilities, and difficulties as well as for the efficient use of the methodology (Seidman 2006: 27, 78). Additionally, as I mentioned before, it is essential that the data are not contaminated by current knowledge or beliefs; the reflective researcher would not invent what should be found in data (Becker 1996: 60 ), which is simultaneously an epistemological position and a position of honesty.

\section{Ethics and Trustful Climate with Participants and the Organisation}

Ethics and the methodological process should be given equal consideration in order to respect the first and achieve rigour in the second. I mention below the main issues raised by this relationship.

Firstly, the interview enquiry is centred on the participant's experiences and meanings of working life. It also relates to the participant's biography and to aspects belonging to his or her intimate self. Participants work in modern and competitive organisations with internal power structures which pursue explicit rationalities as well as non-formal and frequently non-explicit interests. One important ethical issue arises concerning the organisation's tolerance of the results of the investigation. The organisation, as a locus of explicit and non-explicit relationships, opens itself up to an investigation which may make explicit what at some hierarchical level may be considered troublesome. It is important that the top of the hierarchy understands and initially accepts all possible and unpredictable results, otherwise some other type of research is advisable. The researcher must ensure that whatever data are collected during the interviews, the results will not allow the identification of any participant. This is easy when topics expressed are idiosyncratic and will not belong to the ideal type. However, other topics will express the object of study in an essential way and the ideal type construction requires their inclusion. The ethical researcher must decide if the organisation is tolerant enough to accept those topics and if an eventual restriction of the ideal type will jeopardise the ideal description of the object of study. However, there must be no preconceptions about management style. In my professional life, I have found many people in management ready to consider and take advantage of surprises as well as those who are not so open; it should be treated as an empirical issue to be assessed. 
Secondly, during the interview, the intentional analysis process allows the participants to have a different interview experience where many aspects of their previous lives are revisited-some of which might seldom or never have been revisited until the interview. The researcher is looking for the participant's point of view on the objectivities he or she refers to in the interview and maintains epoché, never qualifying or criticising which, for most of the participants, is a new type of experience of reflecting and being heard. However, some participants may not be so co-operative. They may not trust the researcher or the interview process and fear consequences in terms of a future breach of confidentiality. When sensitive organisational themes are touched upon, these wary participants may persistently avoid their discussion or even ask that the subject be changed. In this situation, the researcher should go on to other topics or even terminate the interview. Having touched upon an important topic, but with no experiences or meanings having been described, the researcher may or may not find in other participants a willingness to discuss such topics. In any case, the researcher will reach a conclusion about the collective character of those topics or its absence.

Some participants might be psychologically disturbed and experiencing difficulty in managing their work or private lives. They may welcome this opportunity to reflect and express themselves or, on the contrary, do so with difficulty. In the latter case, the researcher should change the subject or close the interview, perhaps suggesting that he or she might get some help from a professional, or someone in whom the participant can trust. Even if most of the participants enjoy or remain comfortable in the interviews, a few may encounter difficulties. The data may be more limited, sometimes giving important signs, sometimes not. For this reason, the sample initially defined may have to be extended to other participants in the same context. My experience in organisational contexts is that most of the participants are willing to co-operate and the noted difficulties are infrequent; during the last phase of the interview, participants often remark that they had had a pleasant or comfortable experience.

Thirdly, in order to clarify objectives, the process and confidentiality, the researcher should begin each interview with a detailed explanation of these topics. Furthermore, the researcher should emphasise his or her personal and legal commitments to confidentiality, his or her interest in personal experiences and meanings with the sole purpose of achieving what is collective, assuring the participants that personal information will not be disclosed by any means. If the participants accept these explanations and reinforce trust during the interview, the participants will define a situation where they feel safe and will enrich the interviews with many descriptions.

Finally, the formal research proposal for the management should be short, clear, and readily understood with a very brief indication of the theoretical approach, the objective, the details of the proposed process, the context of experience to be studied, and a perspective of the benefits of the knowledge that will be acquired. This requires the approval and the communication of management decisions to the level of the hierarchy that co-ordinates the context to be studied, requesting facilitation. If asked, the researcher will provide additional information. This initial openness from the researcher will encourage an organisational climate in favour of 
the research. The result of this is that the researcher will be allowed to approach the participants during the interviews in such a way that they may feel no more organisational pressure than in their daily work life and simultaneously can respond in a trustful atmosphere within the interview. As proposed by the researcher, top or middle management will communicate the objective and the details of the process to those who work within the context to be studied.

\section{Context, Sample, Saturation, and Generalisation}

The study of a context results in knowledge about it through an ideal type and in terms of collective experiences and meanings. The context is normally a department within an organisation which is definable in terms of a set of characteristics of common experience and which the researcher considers a priori as shared by individuals who also have their particular and different biographies. Hierarchical levels, place dispersion, functions, roles, gender, number of people, and all other organisational categories will define the context diversity as well as context limits. The surrounding environment influences the context structurally and culturally in ways of which individuals may or may not be aware; however, only perceptions born of experience can influence their meanings and action. What could be important, but is not perceived, may indirectly influence perceived elements or may be unimportant and not be taken into consideration.

The initial sample selection has to consider those characteristics and seeks to be representative of all a priori contextual characteristics in this experiential sense. ${ }^{3}$ That is why sample size is important. ${ }^{4}$ I find, from experience, that it should be defined initially in an open way which allows increase or decrease. Sometimes, during fieldwork, it can happen that the researcher finds other important categories and thus needs to increase the sample to ensure that the sample is representative or, having found no more categories, adds participants until effective saturation has been achieved. This means that, from the outset, the researcher does not know how many interviews are to be undertaken and should be prepared to continue interviewing until repetition or redundancy becomes evident (Denzin and Lincoln 2000: 520; Glaser and Strauss 1967), this being the evidence that closes the sample. After a certain number of interviews, the ideal type is achieved and becomes stable when there are no more types of experiences or new meanings which characterise the collective ideally, it being possible that not all the individuals are represented in the ideal type (Weber 1949).

This is a process whereby an idea is confirmed as scientific knowledge about the object of study. The epoché ensures that there is discrimination between genuine meaning and prejudices. In each interview and in its analysis the researcher observes the effect of those common experiences and meanings as evidence

\footnotetext{
3 Patton (2002: 230) and Seidman (2006: 52) affirm that the choice of the sample has the purpose of interviewing people who share experiences and meanings, as those in the context to be studied, as a condition for the avoidance of bias in the construction of the ideal type.

4 Mason (2010: 13-15) remarks that there are numerous references in qualitative methods where, depending on their concrete researches, authors either avoid advising the number of interviews to be made or advise very different numbers.
} 
produced in his realm of habitus. Beginning as a vague and empty form, evidence evolves and keeps itself open to meaning in other participants in a continuous process of renewal of the sense of each interview, until a certain point is reached in which it becomes a fulfilled form when saturation occurs. ${ }^{5}$ The possibility of generalisation beyond this work context and the use of the constructed ideal type outside the context depend on the extent to which it is accepted that other contexts are similar, allowing similar collective experience. It is reasonable to consider that a concrete work context in a company belonging to a very structured industry may have similarities with other concrete work contexts in other similar companies with the same functional role. However, the company's history, its hierarchy and values, as well as specific people and relations within the hierarchy, or any other characteristics, may provide a different kind of work experience.

The Phases and the Technique of the Interview

I will now describe the interview structure as an application of the concepts previously discussed. What I mean by structure is not a systematic set of questions posed by researcher. As stated before, the researcher assumes an attitude of not knowing when suspending knowledge about the context or the participant. Therefore, the proposed structure has three phases ${ }^{6}$ expressed as pathways to be followed in line with the participant's will and openness. These pathways also establish and progressively reinforce confidence between researcher and participant. They seek to collect experiences considered to be important by the participants from their own points of view and with their respective meanings. During each phase the questions are open, enquiring about what is described, then about how it is meant in a spiral way which unveils those important aspects of work as well as important aspects of the participant's habitus. The expected duration of the interview is between 2 and 3 hours so that the participants are not rushed.

The recalling of important experiences is made in the here and now of each interview. The interview context which is being created continuously between researcher and participant is the here of the interview; its quality, when trust is engendered, allows the participant to define a secure situation where expression is not so conditioned by external organisational structure, relations, interests, and power. The now is the present moment of the interview where experiences are recalled, under the participant's actualised habitus, as a new experience in which the objective content (what is recalled) may be revised as well as the ways of meaning in a sedimented habitus. Thus, interviews collect descriptions from participants in the here and now and not as they may have happened from a historical point of view. Participants are asked to describe concrete experiences in that way. When the participants diverge from concrete experiences, stating opinions on general and vague issues, the researcher brings them back to their own experience asking for

\footnotetext{
5 Husserl (1969: 9-11) explains this process as the intentional clarification of the sense of science.

6 The interview structure follows Seidman's (2006: 16-18) proposal with the modifications necessary to approach the sociological object of study.
} 
examples of what they are expressing and applying the intentional analysis to which they refer.

The researcher initiates the first phase, informing the participant of the objective of the research and about confidentiality issues. He also asks the participant to allow a recording which he or she may refuse absolutely, or at any time he or she wants to during the interview. This phase is dedicated to the participant's biography and he or she is asked to recall his or her infancy and youth with some detail of relations with important people such as parents, grandparents, teachers, friends, and other significant people. For the researcher, the objective of this phase is to get a sense of the participant's own way of meaning his or her experiences. The researcher uses this sense to gain a better understanding in the second and following phase of the interview of how each participant means his or her relational experiences at work. Moreover, it also allows an improved understanding of what is specific and idiosyncratic in each one as well as what is collective and will inform the object of study. In other words, the researcher seeks a sense of the participant's habitus as a set of individual ways of viewing the world and specifically of viewing his or her work. This allows the researcher to understand the influence of the habitus on the expression of each individual in order to achieve a better evaluation of the collective and non-idiosyncratic aspects.

The first phase prepares the landscape for the second phase when the researcher asks participants to describe experiences they perceive as important-favourable or unfavourable - in the work they perform as well as to recognise the importance and significance to themselves of these experiences. It is in this second phase that participants give information on aspects that they consider to be important. These might be social relations in the organisation which include accepted values, procedures, hierarchical and informal relations, interests, power, and all the aspects that organisational sociological theory refers to as significant for understanding organisations. It is also in this phase that they refer to the meanings they attribute to those experiences which are personal, but typically can be shared, such as culture, and are important to the sociological description of the work context.

In the third and final phase of the interview, the researcher asks the participant for his or her opinion of the interview and if it had been intrusive at any time. The answer reveals the quality of the relationship established and thus of the quality of the collected information. The question is simple and open and followed by a silence allowing the participant time to reflect and answer. It is an opportunity not only for the participant to evaluate the researcher, but also to evaluate his or her interview experience. Most of the participants remark that they had thought about some aspects of their pasts for the first time in many years and that it had been a good experience; these participants often comment on how their biographies influence those meanings. They may also raise new or revised meanings as well as emotional states experienced during the interview. Frequently, the participants add new information, or start a debate on these topics, producing or renovating meaning, a process that Seidman (2006: 18) referred to as "reflection on the meaning". 
Information Analysis: From the Eidetic Descriptions to the Ideal Type

The information analysis produces two types of results, during five stages.

The first result is the eidetic descriptions resulting from the analysis of important experiences and meanings that were expressed by each participant during the interview. This analysis begins during each interview and continues when the researcher, still focused on the participant, recalls the participant's descriptions and eidetically describes experiences and meanings, always under the epoché. There is an intimate relationship between the initiation of the eidetic process during the interview and its deepening and closure during the analysis of the transcription. Frequently during this stage, there is a need to revisit aspects of the interview, hence, it is highly recommended that the same person-the researcher-executes the interview and the analysis. This process of eidetically revealing what is invariant in each participant gives to the researcher a sense of data saturation as described above. The second result is the ideal type that characterises the participants as a collective. Having the eidetic description of each participant, the researcher will then reflect on them and, maintaining the epoché, construct the ideal type by abstraction. This construction of a type then becomes not an eidetic process such as that performed for each participant, but an abstraction defining what and how the collective tends to be (Weber 1949: 90; Husserl 1982: 166). The result is a solid ideal type that confirms the sense of data saturation.

The two results-each participant's eidetic description and the collective ideal type description - are reached during five stages which analyse the massive amount of information in order to make sense of it (Patton 2002: 432). This information results from the participants' long descriptions which are made longer by the researcher who helps the participants to reflect on their behaviour and thinking in the organisational context. The three-phase interviews often last longer than the scheduled duration because, in order to accomplish the defined pathways, the researcher and the participant go backward and forward many times because the participant's descriptions may be the result of something already reflected upon, as well as the result of what he or she is reflecting upon anew in the interview context. The situation is made worse when recording is not possible, or when the participants ask for the recording to be stopped during the interview. In these cases, as soon as possible and while most of the data is still fresh in the researcher's memory, the researcher should make a longer and more detailed interview description from handwritten notes. Important experiences and meanings may be expressed more in some interviews than others depending on the attention of the researcher and the openness of each participant. The researcher can ask for further clarifications during the interview or, having become aware of specific issues after the interview, be more attentive in future interviews.

The large amount of data that is collected and the evolution in meaning that can be found during the interviews, requires a way of organising the data in order to make it possible to produce some idea of what is important and how that is important to the participant. A complete transcription will exhaust the researcher when performing tasks not related to the eidetic finding of invariant structures in that evolutionary data. Complete transcriptions are required by some authors who 
have made important contributions to phenomenological research in psychology (Giorgi 1985; Hycner 1985; Moustakas 1994), but they are not appropriate for the sociological context of this research. The reason is that, when pursuing an ideal of data verification and scientific demonstration, these authors require the complete transcription of linguistic expressions and their structured analysis as if meanings were already reflected and no strategic definitions of situations were to be taken into account. Rather than attempting a verbatim transcription and the analysis of linguistic meanings, I have found that it is much more useful to execute a transcription in the third person. This procedure reduces parts of the interview to small amounts of text, as a "the participant said that..." mode, but does not exclude what is eidetically important. Indeed, this type of transcription is already part of the eidetic analysis.

The entire process of data analysis consists of the following stages in order to achieve the eidetic descriptions of important work experiences and respective meanings and the ideal type of collective experience and meaning:

Firstly, the researcher listens to each recording as many times as is necessary to recall details so that the eidetic process is based upon the participant's important experiences and how he or she experienced them. When no recording is available, the researcher should read the interview notes attentively with the same objective. Secondly, the researcher transcribes the interview as an indirect discourse, reporting the important experiences of the participant and how they were experienced. Thirdly, the researcher synthesises the important experiences and meanings that the participant expressed when performing the intentional analysis. Fourthly, the researcher synthesises each participant's collective experiences and meanings verifying their eidetic invariance. Finally, after reading all individuals' essential descriptions, the researcher constructs the collective ideal type as described earlier. Only during this final stage do the participant's idiosyncrasies disappear.

\section{Conclusion}

The proposed methodology produces an ideal type describing the collective experiences and meanings and progresses from the individual level to the social level. It also allows, firstly, the confrontation of that ideal type with social theories that reflect on micro and macro aspects of the social relations in an organisation, i.e., once the researcher achieves evidence from the data, a way is open to theoretical interpretation and theory enrichment. Secondly, the ideal type allows confrontations with the commonly-held beliefs inside organisations about the de facto culture and structure.

The comparison between the ideal type and what the top of the hierarchy wants for the organisation will suggest the elaboration of plans of action. This helps contextual collectives and the organisation to improve their competitive edge and, simultaneously, to improve the quality of work experience for their employees. 
Open Access This article is distributed under the terms of the Creative Commons Attribution License which permits any use, distribution, and reproduction in any medium, provided the original author(s) and the source are credited.

\section{References}

Archer, M. (1996). Culture and Agency. Cambridge: Cambridge University Press.

Becker, H. (1996). The Epistemology of Qualitative Research. In R. Jessor, A. Colby, \& R. Schweder (Eds.), Essays on ethnology and human development: Context and meaning in social inquiry. Chicago: Chicago Press.

Bourdieu, P. (1977). Outline of a theory of practice. Cambridge: Cambridge University Press. Braverman, H. (1974). Labour and monopoly capital. New York: Monthly Review Press.

Campbell, C. (1996). The myth of social action. Cambridge: Cambridge University Press.

Crozier, M. (1967). The bureaucratic phenomenon. Chicago: The University of Chicago Press.

Dalton, M. (1959). Men who manage. In M. Granovetter \& R. Swedberg (Eds.), The sociology of economic life. Oxford: Westview Press.

Denzin, N., \& Lincoln, Y. (2000). Handbook of qualitative research. Thousand Oaks: Sage Publications.

DiMaggio, P. (1988). Interest and Agency in Institutional Theory. In L. Zucker (Ed.), Institutional patterns in organizations: Culture and environment. Cambridge, MA: Ballinger.

Giddens, A. (1984). The constitution of society. Outline of the theory of structuration. Cambridge: Polity Press.

Giorgi, A. (1985). Sketch of a psychological phenomenological method. In A. Giorgi (Ed.), Phenomenology and psychological research. Pittsburgh: Duquesne University Press.

Glaser, B., \& Strauss, A. (1967). The discovery of grounded theory: Strategies for qualitative research. Chicago: Aldine Publishing Company.

Goffman, E. (1959). The presentation of self in everyday life. New York: Doubleday.

Gouldner, A. (1971). The coming crisis of western society. London: Heineman.

Habermas, J. (1984). The theory of communicative action (volume 1): Reason and the rationalization of society. Boston: Beacon Press.

Husserl, E. (1960/1926). Cartesian meditations: An introduction to phenomenology (D. Cairns, Trans.). The Hague: Martinus Nijhoff.

Husserl, E. (1969/1929). Formal and transcendental logic (D. Cairns, Trans.). The Hague: Martinus Nijhoff.

Husserl, E. (1970a/1936). The crisis of European sciences and transcendental phenomenology: An introduction to phenomenological philosophy, (D. Carr, Trans.). Evanston: Northwestern University Press.

Husserl, E. (1970b/1901). Logical investigations, volume one (J. N. Findlay, Trans.). London: Routledge \& Kegan Paul Ltd.

Husserl, E. (1970c/1901). Logical investigations, volume two (J. N. Findlay, Trans.). London: Routledge \& Kegan Paul Ltd.

Husserl, E. (1982/1913). Ideas pertaining to a pure phenomenology and to a phenomenological philosophy, first book, general introduction to a pure phenomenology (F. Kersten, Trans.). The Hague: Martinus Nijhoff.

Husserl, E. (1989/1913). Ideas pertaining to a pure phenomenology and to a phenomenological philosophy, second book, studies in the phenomenology of constitution ( $\mathrm{R}$. Rojcewicz and A. Schuwer, Trans.). Dordrecht: Kluwer Academic Publishers.

Husserl, E. (1991). On the phenomenology of the consciousness of the internal time (J. B. Brough, Trans.). Dordrecht: Kluwer Academic Publishers.

Husserl, E. (2001/1920). Analysis concerning passive and active synthesis: Lectures on transcendental logic (A. Steinbock, Trans.). Dordrecht: Kluger Academic Publishers.

Hycner, R. (1985). Some guidelines for the phenomenological analysis of interview data. Human Studies, 8, 279-303.

Mason, M. (2010). Sample size and saturation in PhD studies using qualitative interviews. Forum Qualitative Social Research, 11(3), 13-15.

Merton, R. (1968/1949). Social theory and social structure. New York: Free Press. 
Meyer, J., \& Rowan, B. (1977). Institutionalised organizations: Formal structure as myth and ceremony. In W. Powell, \& P. DiMaggio (Ed.) (1991), The new institutionalism in organizational analysis. Chicago: The University of Chicago Press.

Moran, D. (2001). Introduction. In E. Husserl (Ed.), Logical investigations, volume one (J. N. Findlay, Trans.). London: Routledge \& Kegan Paul Ltd.

Moustakas, C. (1994). Phenomenological research methods. London: Sage Publications.

Mouzelis, N. (1991). Back to sociological theory. The construction of social orders. London: Macmillan. Parsons, T. (1960). Structure and process in modern societies. New York: The Free Press.

Patton, M. (2002). Qualitative research \& evaluation methods. London: Sage Publications.

Sainsaulieu, R. (1977). L'Identité au Travail (The identity at work). Paris: Presses de la Fondation Nationale de Sciences Politiques.

Sainsaulieu, R. (2009). Empresa e Produção de Identidade - Prefácio (Enterprise and identity productiopreface). In D. Pimentel (Ed.), Empresa e Identidades Profissionais (Enterprise and professional identity). Lisbon: Argusnauta.

Scott, J. (1990). Domination and the arts of resistance: Hidden transcripts. New Haven: Yale University Press.

Scott, W. (2004). Reflections on a half-century of organizational sociology. Annual Review of Sociology, $30,1-21$.

Seidman, I. (2006). Interviewing as qualitative research. New York: Teachers College Press.

Silverman, D. (1970). The theory of organizations. London: Heinemann Educational Books.

Steinbock, A. (1997). Back to the things themselves: Introduction. Human Studies, 20, 127-135.

Weber, M. (1949/1924). On the methodology of the social sciences. Illinois: The Free Press of Glencoe. Zahavi, D. (2003). Husserl's phenomenology. Stanford: Stanford University Press. 